\title{
A new genus and species of Baetidae (Insecta: Ephemeroptera) from Brazil
}

\author{
Paulo Vilela Cruz ${ }^{1,3 *}$, Frederico Falcão Salles ${ }^{2}$ and Neusa Hamada ${ }^{3}$ \\ ${ }^{1}$ Programa de Pós-graduação em Entomologia, Instituto Nacional de Pesquisas da Amazônia (INPA), CEP 69060-001, Manaus, \\ Amazonas, Brazil \\ ${ }^{2}$ Centro Universitário Norte do Espírito Santo, Universidade Federal do Espírito, Santo, Brazil, CEP 29933-415, São Mateus, \\ Espírito Santo, Brazil \\ ${ }^{3}$ Coordenação de Biodiversidade (CBio), Instituto Nacional de Pesquisas da Amazônia (INPA), CEP 69060-001, Manaus, \\ Amazonas, Brazil
}

Received 3 August 2012; Accepted 30 November 2012

\begin{abstract}
A new genus (Callibaetoides) and species (Callibaetoides caaigua) of Baetidae (Ephemeroptera) is described based on nymphs and adults of both genders collected in forested areas of Amazonia and Mata Atlântica biomes. The nymphs were collected from leaf packs accumulated in the backwaters of small streams. The genus and species can be easily distinguished from other members of the family in South America by the following combination of characteristics: male and female imagos with costal process of hind wing centrally located and strongly projected; marginal intercalary veins long and paired in male imago; nymphs with deep medial emargination of labrum, maxillary palp three segmented and third segment of labial palp quadrangular.
\end{abstract}

Key words: aquatic insects / mayfly / taxonomy / neotropics / new taxon

\section{Introduction}

The knowledge concerning the faunal diversity of the family Baetidae (Ephemeroptera) in the neotropics was neglected until the decade of 1990 (Gattolliat and Nieto, 2009). Since then, however, a series of studies have increased considerably the knowledge about the taxonomy and systematics of the family (Lugo-Ortiz and McCafferty, 1995, 1996a, 1996b, 1996c, 1996d, 1996e; Lugo-Ortiz and McCafferty, 1997; Salles and Batista, 2004; Salles and Francischetti, 2004; Salles et al., 2004, 2005; Salles, 2007; Nieto and Richard, 2008; Salles and Polegatto, 2008; Nieto, 2010). Currently, the neotropics have records of 28 genera and more than 210 species, most of them endemic (Gattolliat and Nieto, 2009; Nieto and Derka, 2011).

Most of the studies focused on Baetidae diversity from lotic habitats, while the number of publications on lentic areas or on backwaters of streams demonstrate few advances in the last decade and concentrated on Brazilian Amazonia and Mata Atlântica forests (or biomes), allowing the description of several new species

\footnotetext{
*Corresponding author: pvilelacruz@gmail.com
}

and unknown stages (e.g., Nieto and Salles, 2006; Cruz et al., 2009; Falcão et al., 2010; Cruz et al., 2011a, 2011b; Salles et al., 2011); however, these regions can still be considered as areas that have much of their respective faunas unknown (Salles, personal observation and several new species not yet published).

As a contribution to diminishing these gaps, the main objective of this study is to describe a new genus and species, based on nymphs and adults collected in backwaters of small streams, in the Brazilian Amazonia and Mata Atlântica forests.

\section{Material and methods}

Descriptions followed the standardization proposed by Hubbard (1995) and were made using the DELTA (DEscription Language for TAxonomy) open software (Dallwitz, 1980). The drawings were made using a ZEISS Standard 20 microscope with camera lucida, and photographs were taken using a stereoscopic ZEISS Stemi 2000-C microscope with a Nikon CoolPix 5700 camera; the pictures were combined using the CombineZ5 open software; the final illustrations were prepared according to Coleman (2003, 2006). 
A few specimens were dehydrated in a graded ethanol series, dried by critical point-method, and mounted on SEM stubs and sputter coated with gold; then they were observed and photographed with Leo VP 435 scanning electron microscope.

Stage associations were made using rearing techniques suggested by Edmunds et al. (1976). The female subimago was reared with the same technique and compared with a female imago from a light trap.

The material examined is housed in the following institutions: Invertebrate Collection of the Instituto Nacional de Pesquisas da Amazônia, Manaus, Brazil (INPA), Coleção Zoológica Norte Capixaba of the Universidade Federal do Espírito Santo (CZNC), São Mateus, Brazil and Fundación-Instituto Miguel Lillo, Tucumán, Argentina (IFML).

Callibaetoides gen. nov.

Type species. Callibaetoides caaigua sp. nov.

\section{Diagnosis}

Male imago. (1) Dorsal portion of turbinate eyes with inner margins divergent anteriorly (Fig. 1(A)); (2) forewing with paired and long marginal intercalary veins ( $2.5 \times$ distance between adjacent longitudinal vein) (Fig. 2(A)); (3) hind wing with two longitudinal veins (Fig. 2(C)); (4) costal process strongly projected (length $1.5 \times$ width of hind wing), apex posteriorly directed, centrally located (Fig. 2(C)); (5) forceps segment II narrow medially (Fig. 2(E)).

Female imago. (1) Marginal intercalary veins single and short (Fig. 2(B)); (2) hind wing with two longitudinal veins (Fig. 2(B)); (3) costal process strongly projected (length $1.5 \times$ width of hind wing), apex posteriorly directed, centrally located (Fig. 2(D)).

Mature nymph. (1) Anterior margin of labrum with deep medial emargination (Fig. 3(B)); (2) mandibles with incisors deeply cleft (Figs. 3(D) and (E)), with inner set at oblique angle with outer set (Figs. 3(D) and (E)); (3) mandibles with tuft of setae between prostheca and mola (Figs. 3(D) and (E)); (4) maxillary palp with three segments (Fig. 3(G)); (5) labial palp without distomedial projection (Fig. 3(I)), third segment quadrangular not expanded (Fig. 3(I)); (6) hind wing pad present, though very small; (7) tibiae without a subproximal arc of long, fine setae; (8) tarsal claw of foreleg slender with two rows of denticles increasing in size distally (Figs. 4(D) and 7(C)); (9) gills on abdominal segments I to VII; (10) gills with anal extension folded (Figs. 5(A-G)); (11) terminal filament $0.9 \times$ shorter than cerci; (12) body with scale bases (Figs. 7(A) and (B)).

\section{Generic description}

Male Imago. Head (Figs. 1(A) and (C)). Dorsal portion of turbinate eyes elliptical, divergent anteriorly. Thorax (Figs. 1(A) and (C)). Anteronotal protuberance rounded (Figs. 1(A) and (C)); metascutellar protuberance absent (Figs. 1(A) and (C)). Marginal intercalary veins of forewing paired, length of each intercalary vein

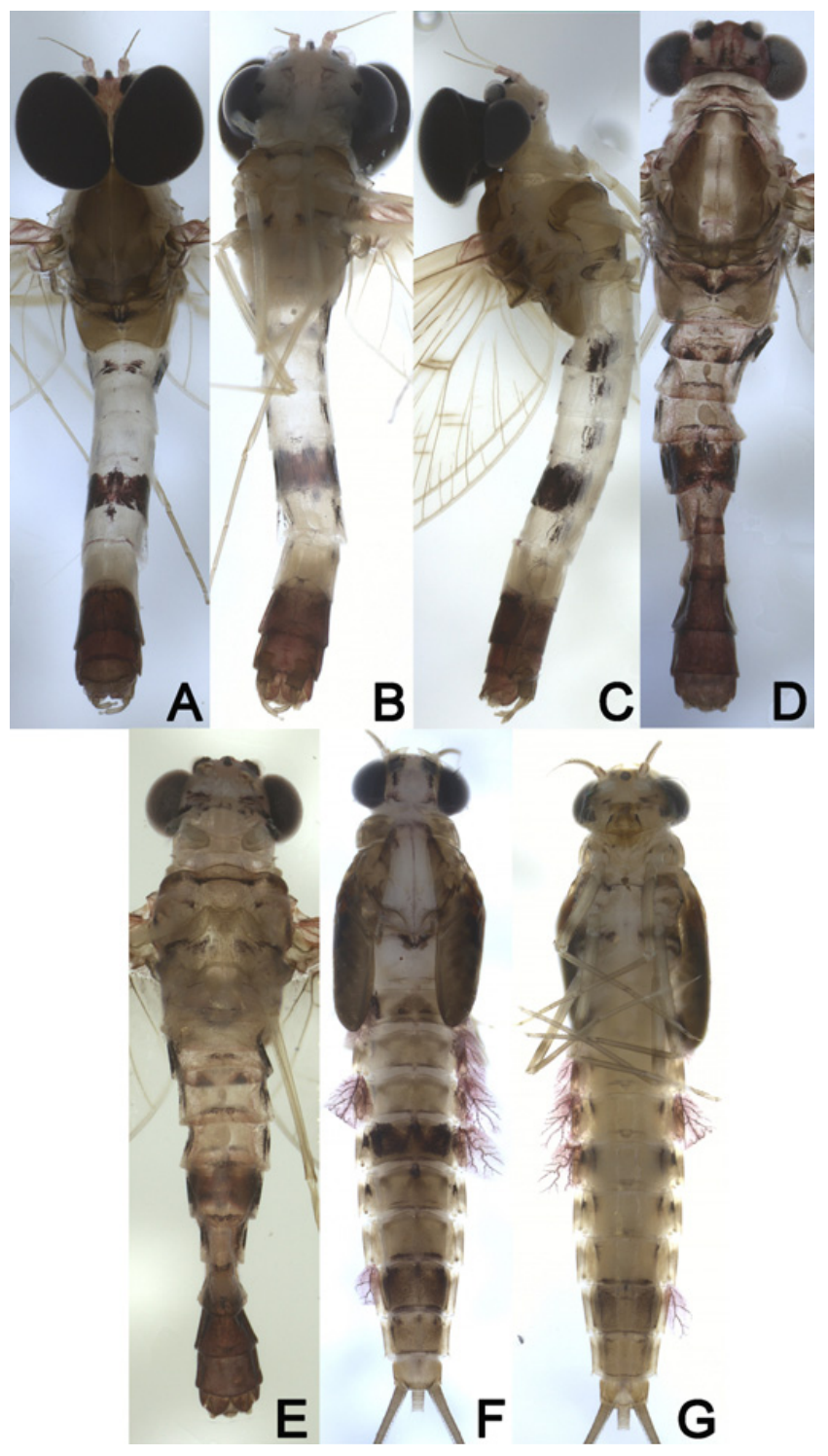

Fig. 1. (A) Male imago dorsal view; (B) male imago ventral view; (C) male imago lateral view; (D) female imago dorsal view; (E) female imago ventral view; (F) nymph dorsal view; (G) nymph ventral view.

$2.5 \times$ distance between adjacent longitudinal veins (Fig. 2(A)). Hind wing with two longitudinal veins; costal process inverted L shaped strongly projected (length $1.5 \times$ width of hind wing), apex posteriorly directed, centrally located (Fig. 2(C)). Abdomen. Genitalia (Fig. 2(E)). Forceps segment II narrow medially; segment III clavate and short.

Female Imago. Thorax (Figs. 1(D) and (E)). Anteronotal protuberance rounded (Fig. 1(D)). Forewing with marginal intercalary veins single and short (Fig. 2(B)). Hind wing with two longitudinal veins; costal process (Fig. 2(D)) strongly projected, length $1.5 \times$ width of hind wing, apex posteriorly directed, centrally located.

Mature nymph (Figs. 1(F) and (G)). Head. Frons flat. Labrum (Fig. 3(B)) with deep V-shaped medial emargination. Mandibles (Figs. 3(D) and (E)) with incisors deeply 
cleft in two sets; inner set of incisors at oblique angle with outer set, with tuft of setae between prostheca and mola; denticles of mola not constricted. Maxilla broad, outer margin with fine and simple setae, maxillary palp three segmented. Labium (Fig. 3(I)). Labial palp segment II without distomedial projection; segment III quadrangular. Thorax. Hind wing pad present. Legs (Figs. 4(D)-(F)). Tarsal claw slender with two rows of denticles increasing in size distally. Abdomen. Gills (Figs. 5(A)-(G)) on segments I-VII, anal extensions folded. Terminal filament $0.9 \times$ shorter than cerci.

Etymology. The generic name was chosen by the similarity of the new genus with Callibaetis Eaton. The gender is masculine.

In order to accommodate Callibaetoides gen. nov. we modified the key for South American genera of Baetidae proposed by Domínguez et al. (2006) p. 57, as follows:

\section{Key to male imago}

13(12) Hind wings with subquadrangular costal projection (Domínguez et al., 2006, Fig. 54(F)).................................13a - Hind wings with pointed costal projection (Domínguez et al., 2006, Fig. 30(C)) .... 14

$13 \mathrm{a}$ Hind wings with subquadrangular costal projection located on basal third .......................................Paracloeodes $13 \mathrm{a}^{\prime}$ Hind wings with subquadrangular costal projection located centrally Callibaetoides, new genus

\section{Key to nymphs \\ 3(2) Abdominal gills with two lamellae (Figs. 29(M)-(O)).. $3 a$ - Abdominal gills with a single lamella (Fig. 9(J)) ................ 4 3a Third segment of labial palp rounded to ovate, dorsal surface concave (Domínguez et al., 2006, Fig. 29(G)) ........................................................... Callibaetis 3a' Third segment of labial palp subquadrangular, distal margin concave, dorsal surface flat ........ Callibaetoides, new genus}

Callibaetoides caaigua $\mathbf{s p . ~ n o v . ~}$

\section{Diagnosis}

Although no comparative species of the genus are known we expect that the following characteristics may prove to be of importance for specific diagnosis. However, as this genus remains monospecific, those characters used in the generic section can also be used for specific identification.

Male imago. (1) Base of costal vein of forewing reddish, membrane near cross veins darker (Fig. 2(A)); (2) hind wing with first vein incomplete and second complete (Fig. 2(C)); (3) abdominal terga V, VIII, IX, and X brown (Fig. 1(A)); (4) forceps segment I with inner margin undulated (Fig. 2(E)); (5) posterior margin of styliger plate with small rounded projection (Fig. 2(E)).

Female imago. (1) Costal vein base of forewing reddish, membrane near cross veins darker (Fig. 2(B)); (2) marginal intercalary veins absent between veins $\mathrm{Sc}$ to $\mathrm{R}$ and $\mathrm{CuA}$ to A (Fig. 2(B)); (3) length of each intercalary vein $1.0 \times$ or less distance between adjacent longitudinal veins (Fig. 2(D)); (4) hind wing with first vein incomplete and

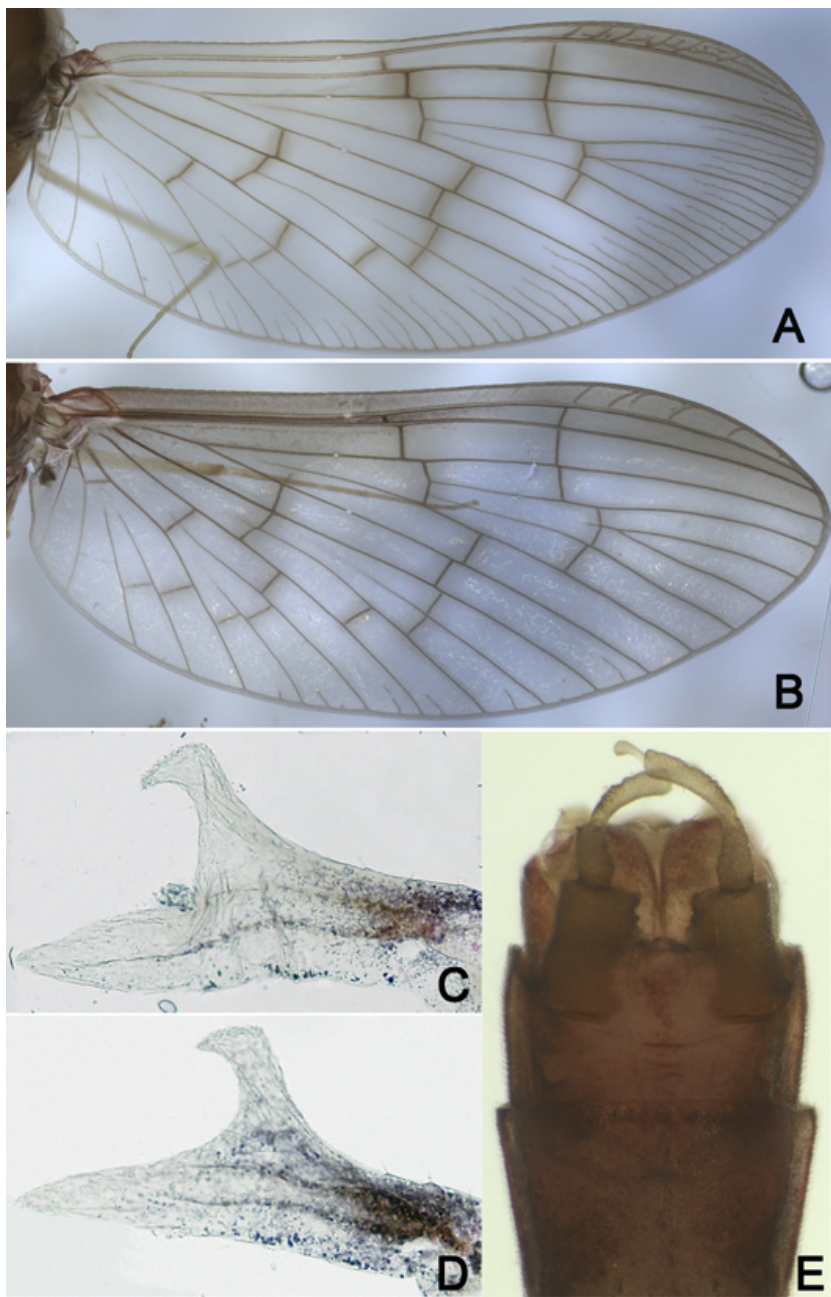

Fig. 2. (A) Male forewing; (B) female forewing; (C) male hind wing; (D) female hind wing; (E) male genitalia.

second complete (Fig. 2(D)); (5) abdominal terga V, VIII, IX, and X brown (Fig. 1(D)).

Mature nymph. (1) Anterior margin of labrum with robust and apically multi-flagellated setae (Figs. 2(C) and 6(B)); (2) lingua longer than superlingua (Figs. 3(F) and $6(\mathrm{C})$ ); (3) crown of galea-lacinia with three denticles on protuberance (Fig. 3(G)); (4) apex of paraglossa with one tuft of simple, fine and long setae (Fig. 3(J)); (5) costal rib present on gills III-VII (Fig. 5(C-F)); (6) cercus with long spines on every three segments (Figs. 5(K) and $7(\mathrm{~F})$ ); (7) terminal filament without long spines (Figs. 5(J) and $7(\mathrm{E}))$.

\section{Species description}

Male Imago (Figs. 1(A)-(C)). Length: body $4.2 \mathrm{~mm}$; forewing $4.0 \mathrm{~mm}$; hind wing $0.3 \mathrm{~mm}$; antenna $0.7 \mathrm{~mm}$; tibia I $0.9 \mathrm{~mm}$; tibia II $0.6 \mathrm{~mm}$; tibia III $0.7 \mathrm{~mm} .(n=1)$. Head. Coloration yellowish. Turbinate portion of compound eye black. Antenna with scape and pedicel reddish yellow, flagellum yellowish. Length of dorsal portion of 


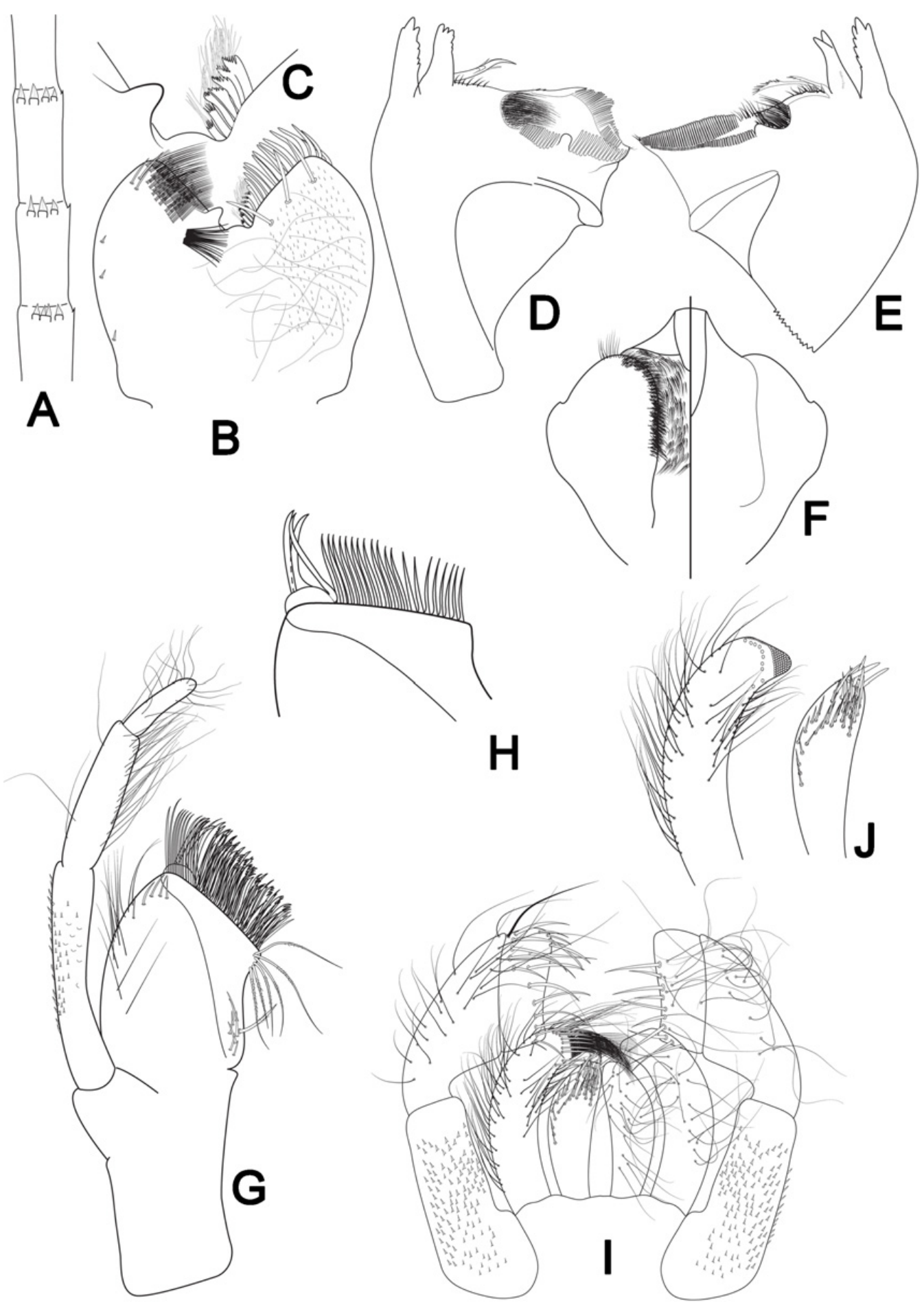

Fig. 3. Nymph structures in optical microscope. (A) Antenna; (B) labrum (left, ventral view; right, dorsal view); (C) details of anterior margin of labrum; (D) left mandible; (E) right mandible; (F) hypopharynx (left, dorsal view; right, ventral view); (G) maxilla; (H) details of maxilla; (I) labium (left, dorsal view; right, ventral view); (J) details of glossa and paraglossa in dorsal view.

turbinate eyes $0.8 \times$ width; stalk height $1.0 \times$ dorsal portion height (lateral view) (Figs. 1(A) and (C)). Thorax. Anteronotal protuberance, mesoscutum, submesoscutum, posterior scutal protuberance, and scutellum (Figs. 1(A) and (C)) light brown. Legs yellowish. Leg I: tibia $1 \times$ length of femur; tarsi $1 \times$ length of femur.
Leg III: tibia $0.7 \times$ length of femur; tarsi $0.6 \times$ length of femur. Forewing brownish yellow, apically little darker, base of costal vein reddish, membrane near cross veins darker; stigmatic area with 6 cross veins interconnected and touching Sc vein; all veins light brown darker; marginal intercalary veins paired except between veins 


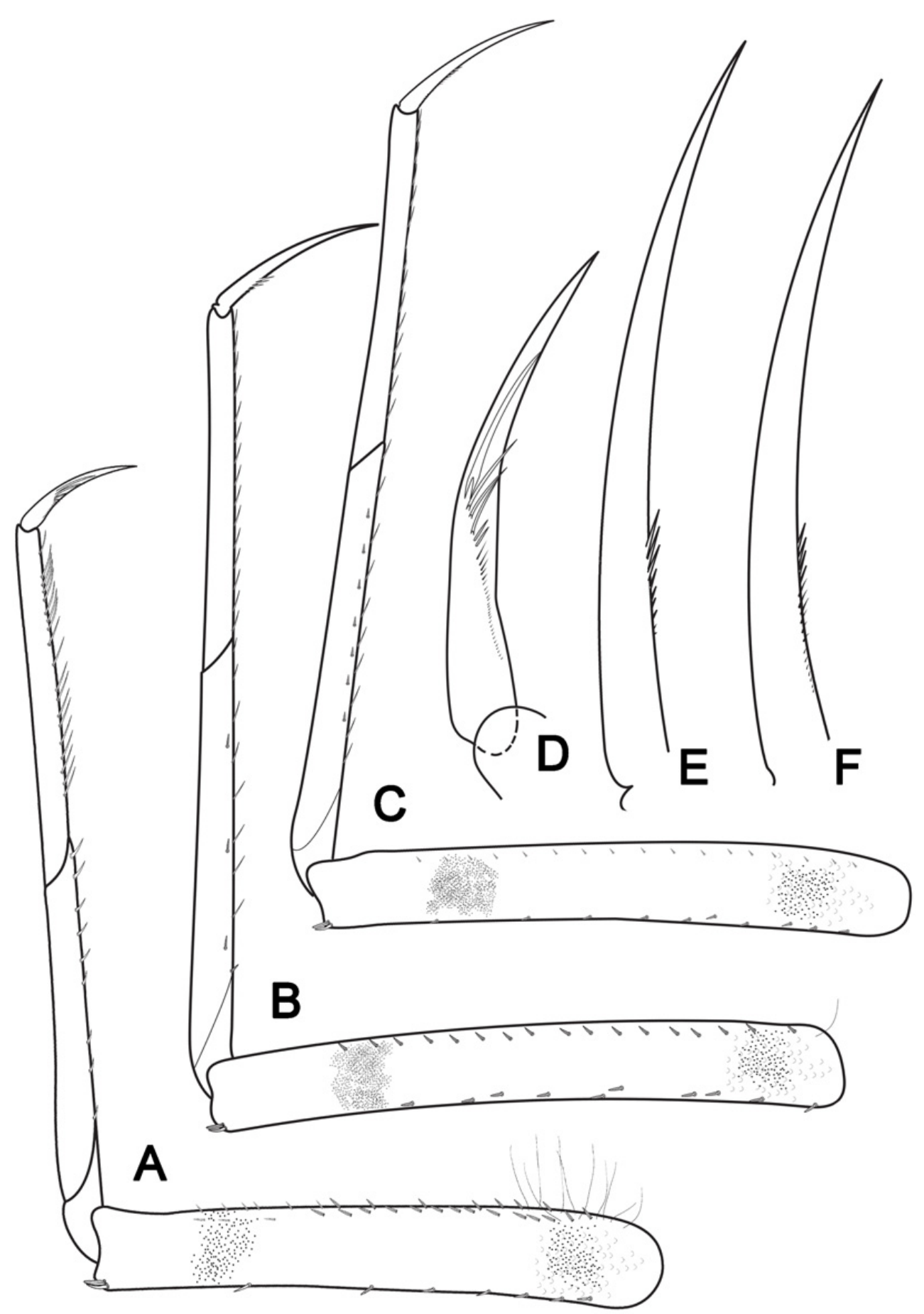

Fig. 4. Nymph structures in optical microscope. (A) Foreleg; (B) mid leg; (C) hind leg; (D) details of foretarsi; (E) details of mid tarsi; (F) details of hind tarsi.

$\mathrm{ICu}_{1}$ and $\mathrm{A}$; forewing (Fig. 2(A)) about $2.5 \times$ width. Hind wing hyaline with brownish basal mark; with two longitudinal veins, first incomplete and second complete. Abdomen. Abdominal terga II medially with one brownish mark near posterior margin; segments III-VII white, with posterior margin brownish; segments V, VIII, IX and X brown; segment II laterally with large black mark, other segments laterally with small black mark. Abdominal sterna II-VII white, with posterior margin brownish; segments VIII, IX and X (Figs. 1(A) and (B)) dark brown. Forceps segment I with inner margin undulated; $0.7 \times$ length of segment II; distance between inner margins of forceps $0.4 \times$ distance between lateral margins of forceps. Forceps segment III (Fig. 2(E)) clavate, $2.5 \times$ as 

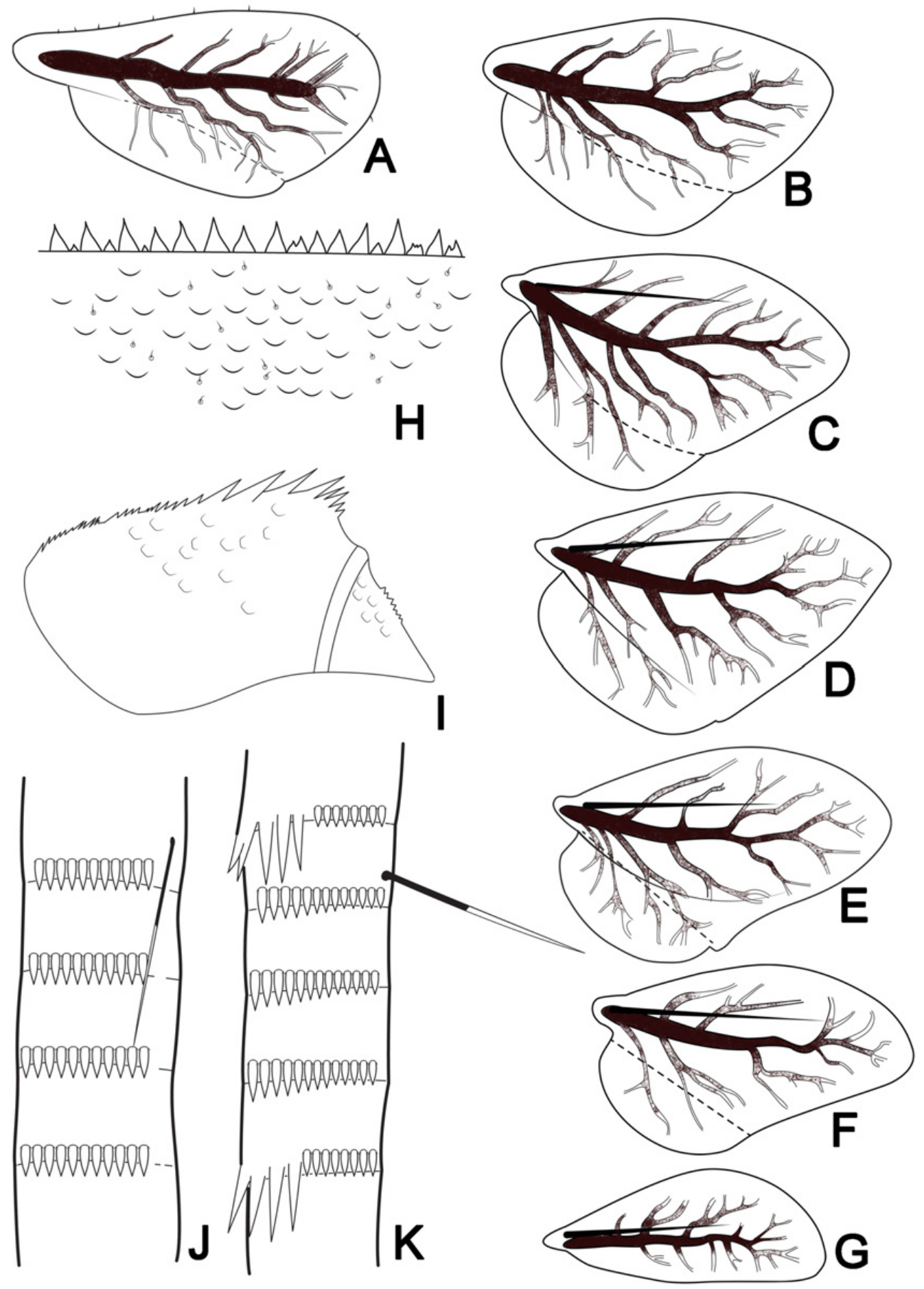

Fig. 5. Nymph structures in optical microscope. (A) Gill I; (B) gill II; (C) gill III; (D) gill IV; (E) gill V; (F) gill VI; (G) gill VII; (H) posterior margin of abdominal tergum IV; (I) paraproct; (J) terminal filament; (K) cerci.

long as wide; $0.2 \times$ length of segment II. Posterior margin of styliger plate (Fig. 2(E)) with small rounded projection. Caudal filaments brownish yellow. Genitalia. Forceps reddish brown.

Female Imago (Figs. 1(D) and (E)). Length: body 4.2 $\mathrm{mm}$; cerci $9.6 \mathrm{~mm}$; forewing $4.0 \mathrm{~mm}$; hind wing $0.3 \mathrm{~mm}$; antenna $0.3 \mathrm{~mm}$; tibia II $0.9 \mathrm{~mm}$; tibia III $0.7 \mathrm{~mm}(n=2)$.
Head. Coloration reddish yellow with two black marks; compound eyes black. Antenna with scape, pedicel and flagellum brownish. Thorax. Anteronotal protuberance, mesoscutum, submesoescutum, posterior scutal protuberance, scutellum brownish (Fig. 1(D)) yellow. Legs brownish yellow. Leg II: tibia $0.8 \times$ length of femur; tarsi $0.6 \times$ length of femur. Leg III: tibia $0.7 \times$ length of 
femur; tarsi $0.6 \times$ length of femur. Wings. Forewing (Fig. 2(B)), costal vein base of forewing reddish, membrane near cross veins darker, $\mathrm{C}, \mathrm{Sc}$ and $\mathrm{R}_{1}$ area darker; veins light brown; stigmatic area with minimum of 4 cross veins touching Sc vein; marginal intercalary veins absent between veins $\mathrm{Sc}$ to $\mathrm{R}$ and $\mathrm{CuA}$ to $\mathrm{A}$; length of each intercalary vein $1 \times$ or less distance between adjacent longitudinal veins; length of forewing (Fig. 2(B)) about $2.4 \times$ width. Abdomen (Figs. 1(D) and (E)). Abdominal terga II with one brownish mark near posterior margin, segments III, IV, VI and VII light brown with posterior margin brownish. Abdominal sterna II-VII white, with posterior margin brownish, segments VIII, IX and $\mathrm{X}$ brown. Caudal filaments brownish yellow.

Mature nymph (Figs. 1(F) and (G)). Length: body: $5 \mathrm{~mm}$; cerci: $2.5 \mathrm{~mm}$. $(n=2)$. Head. Coloration: brownish yellow with two brown marks near eyes. Antenna brownish yellow. Turbinate portion of male compound eye black. Antenna (Fig. 3(A)) with spines and fine, simple setae on apex of each segment. Lateral branch of epicranial suture curved. Labrum (Figs. 3(B) and 6(A)). Length about $0.8 \times$ maximum width; mediolaterally with robust and simple spine-like setae, medially with robust and apically multi-flagellatedsetae and two robust and rounded denticles (Figs. 3(C) and 6(B)); dorsally with many, long, fine, simple setae and small spines scattered over surface, dorsal surface near distal margin with three robust setae; ventrally with short spine-like setae near lateral margin, anterolaterally with three to four long and robust spine-like setae, near distal margin with one row of fine, long and simple setae, and posteriorly with five or six rows offine, long and simple setae (Fig. 3(B)). Left mandible (Fig. 3(D)) with incisors with $7+3$ denticles, inner incisor with three to seven small denticles on inner margin; prostheca robust, medially with spines, apical half serrated; margin between prostheca and mola straight; subtriangular process narrow, apex below level of area between prostheca and mola; tuft of setae at apex of mola present; lateral margins convex; bare dorsally. Right mandible (Fig. 3(E)) with incisors with $7+2$ denticles; prostheca slender, bifurcated at base, outer lobe shorter, lobes pectinate; margin between prostheca and mola slightly convex; tuft of setae at apex of mola present; lateral margins convex; bare dorsally. Hypopharynx. Lingua (Fig. 6(C)) longer than superlingua; superlingua (Fig. 3(F)) rounded with small expansion with short, fine, simple setae scattered over lateral and distal margin. Maxilla (Fig. 3(H)). Crown of galea-lacinia with 3 denticles on a protuberance; with three rows of setae, one dorsal row of robust and simple spine-like setae, one ventral row of robust and apically bipectinate (brush-like), and between those one row of robust and strongly pectinate setae (fork-like) (Figs. 6(D), (E), (F) and (G)). Medial protuberance of galea (Fig. $3(\mathrm{G})$ ) with $1+7$ spinelike setae. Maxillary palp long, $2.0 \times$ length of galealacinia; palp segment II $0.7 \times$ length of segment I; palp segment III $0.5 \times$ length of segment II; maxillary palp (Fig. 6(H)) segment I covered with small spines, scale bases and fine setae, segment II ventral margin with two rows of fine, simple and long setae, dorsal margin with few fine and simple setae, segment III (Fig. 3(G)) covered with fine, simple and long setae. Labium (Fig. 3(I)). Glossa (Figs. 3(I) and (J)) narrow and shorter than paraglossa; inner margin bare; apex with three spine-like setae; outer margin bare (Fig. 3(J)); ventral surface scattered with long, fine and simple setae, apical third of dorsal surface covered with robust spine-like setae increasing in length apically. Paraglossa (Figs. 3(I) and (J)) curved inward and truncated at apex; ventral surface covered with simple, fine and long setae; apex of dorsal surface with one tuft of simple, fine and long setae, near apex with one arc of robust and long spine-like setae. Labial palp with segment I as long as segments II and III combined; segment I dorsally and ventrally covered with spines; segment II with dorsal and ventral surface covered with simple, fine and long setae; segment III length $0.3 \times$ width, dorsal surface of segment III with one row of robust and long spine-like setae near posterior margin, one row of 5-6 robust and long spinelike setae near anterior margin, and one row of 4-5 spinelike setae on outer margin near anterior margin; ventral surface of segment III with few fine, simple and long setae, anterior margin with one row of robust and long spine-like setae. Thorax. Brownish. Foreleg (Fig. 4(A)). Brownish yellow, femur with two brown marks, one near base and other near apex. Ratio of foreleg 1.3:(0.7 mm):0.8:0.3. Forefemur. Anterior surface covered with scale bases and scales; length about $7.5 \times$ maximum width; dorsal and ventral margin with one row of short spine-like setae; length of setae about $0.1 \times$ maximum width of femur; ventral and dorsal margin of anterior surface with row of blunt setae (Fig. 7(D)), base with patch of fine and simple setae on ventral margin. Foretibia. Ventral margin with few short, fine and simple spine-like setae. Foretarsus. Dorsal margin with few fine and simple setae; ventral margin with two rows of spine-like setae. Tarsal claw with apical denticles inserted laterally and basal denticles inserted ventrally (Figs. 4(D) and 7(C)). Middle and hind legs (Figs. 4(B) and (C)). Tibiae with two rows of short spine-like setae, one ventrally and other near ventral margin; tarsi with two rows of spine-like setae; denticles of claws shorter (Figs. 4(E) and (F)). Abdomen (Figs. 1(F) and $(\mathrm{G})$ ). Abdominal tergum II with one brownish mark near posterior margin, abdominal terga III, IV, VI, and VII with posterior margin brownish, abdominal terga V, VIII darker, abdominal tergum IX with one lateral and medial brown mark near anterior margin; abdominal sterna II to VII with brown posterior margin, abdominal sternum VIII darker. Terga surface (Figs. 5(H) and 7(A)) creased with scale-bases and scales. Posterior margin (Fig. 5(H)) with spines basally broad on abdominal terga II-X. Sternum surface (Fig. 7(B)) creased with scale-bases and scales. Gills (Figs. 5(A)-(G)). Lamella reddish; tracheae reddish brown, extending from main trunk to outer margin, all with one anal extension except on gill VII, anal extensions folded; costal rib present on gills III-VII, anal rib reduced on all gills. Gill I $1.5 \times$ segment II. Gill IV $1.5 \times$ segment V. Gill VII $1.5 \times$ segments VIII. Paraproct with about 30 marginal spines, surface with 

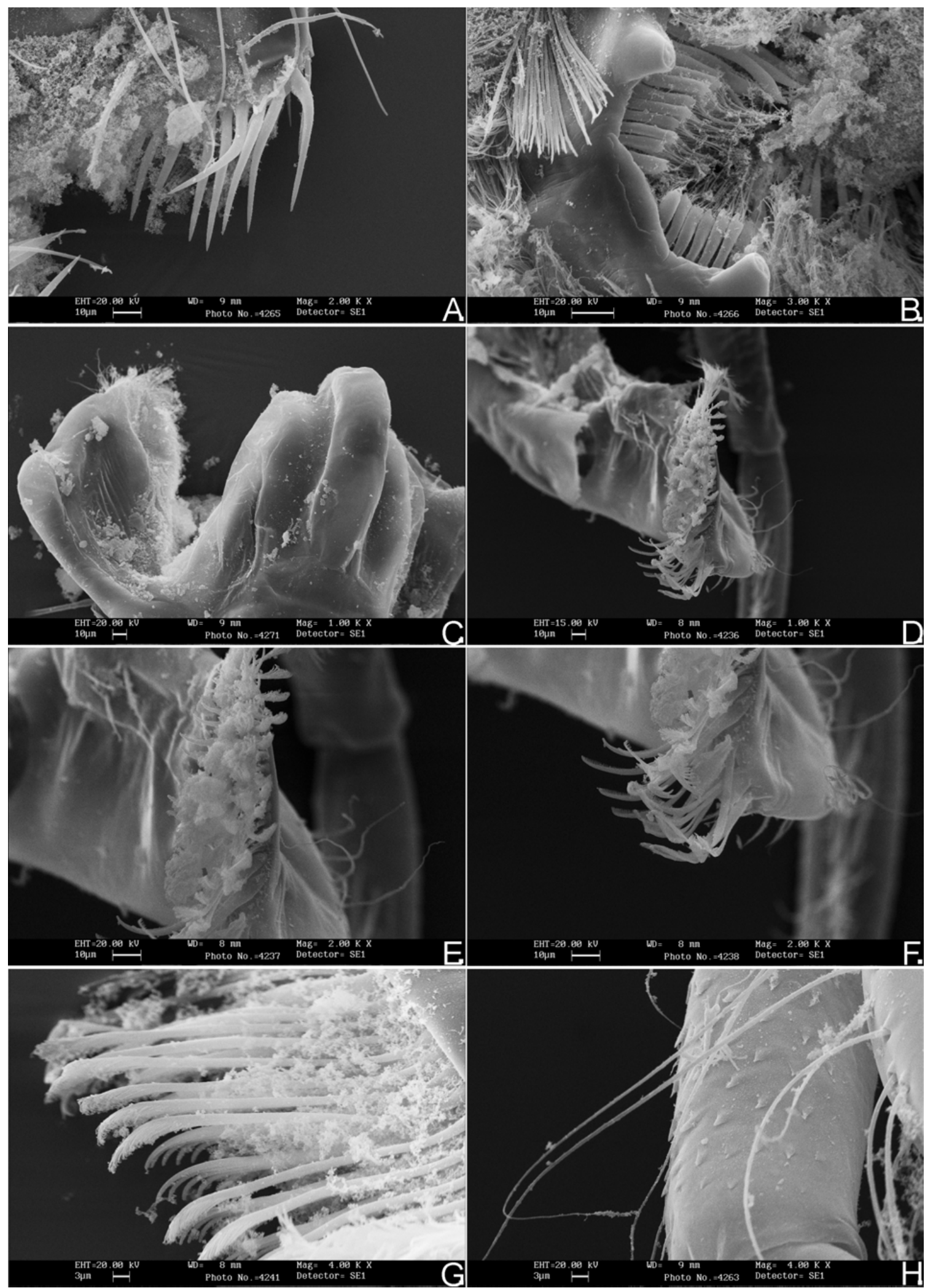

Fig. 6. Nymph structures in electron microscope. (A) Setae on anterolateral margin of labrum in dorsal view; (B) setae on medial margin of labrum in ventral view; (C) hypopharynx in ventral view; (D) maxilla in frontal view; (E) details of maxilla in frontal view; (F) details of maxilla in frontal view; $(\mathrm{G})$ details of maxilla in lateral view; $(\mathrm{H})$ details of segment I of maxillary palp. 


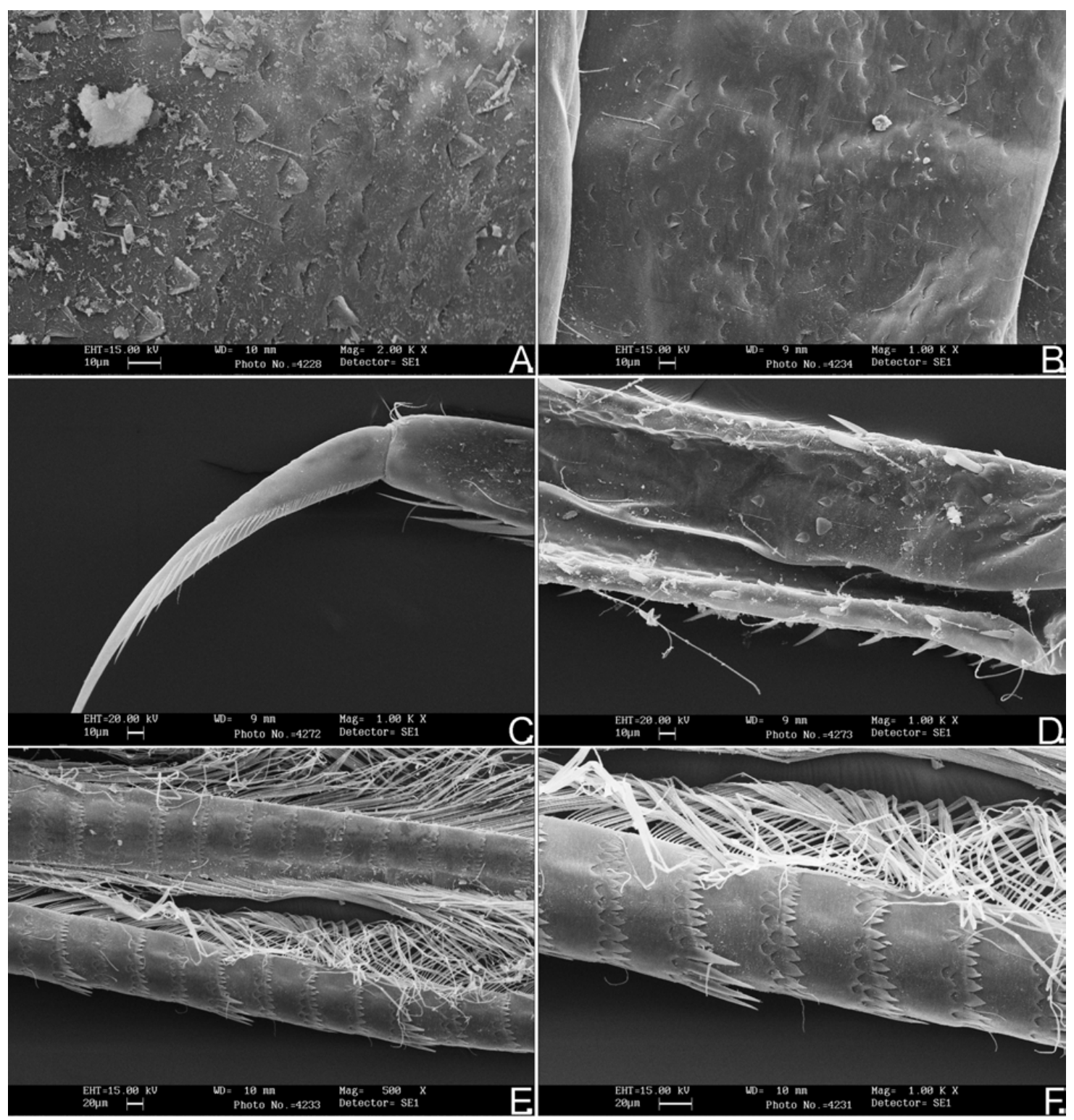

Fig. 7. Nymph structures in electron microscope. (A) Abdominal terga surface; (B) abdominal sterna surface; (C) details of foreclaw; (D) details of forefemur; (E) cerci and terminal filament; (F) details of cerci.

scale-bases, postero-lateral extension with minute marginal spines (Fig. 5(I)). Terminal filament (Figs. 5(J) and 7(E)) with posterior margin of segments with spines on each segment. Cerci (Figs. 5(K) and 7(F)) with posterior margin of segments with spines on each segment and long spines on every three segments. Caudal filaments with flattened setae, basal half dark.

Etymology. The specific epithet is a free union of two words of the Tupí-Guarani language, a Brazilian native indigenous language (caa, meaning leaf and ig, meaning water), this word is a reference to the substrate where the nymphs of this species were collected.

Material examined: HOLOTYPE: 1 nymph, BRAZIL, Amazonas, Manaus, Reserva Florestal Ducke, Tinga stream 2 56'41.0"S 59 57'22.0"W, root and leaves, 27.iii.2010, E.L. Belmont col (INPA). PARATYPES:
BRAZIL, Amazonas, Manaus, Reserva Florestal Ducke, Barro Branco stream 02 55'46.7"S 059 58'22.0"W: 1 male imago, 10.iii.2009, P.V. Cruz col., reared (UFES); 5 nymphs, 21.i.2010 (INPA); 1 nymph, 10.iii.2011 (IFML). BRAZIL, Amazonas, Manaus, BR 174, km 18: 1 nymph 16.viii.2009, F.F.Salles col. (UFES). BRAZIL, Amazonas, Manaus, Reserva Florestal Ducke, Tinga stream $2^{\circ} 56^{\prime} 41.0^{\prime \prime S}$ 59॰57'22.0"W: 1 nymph, 24.iii.2010, E.L. Belmont col (IFML); 2 nymphs, root and leaves, 27.iii. 2010, E.L. Belmont col (UFES). BRAZIL, Amazonas, Manaus, BR 174, Viana's farm: 1 nymph, 23.ii.2010, E.L. Belmont col. (INPA). BRAZIL, Amazonas, Manaus, Reserva Florestal Ducke, Ipiranga stream 2 59'36.3"S 59 53'25.5"W, 1 nymph, v.2010, (INPA). BRAZIL, Amazonas, Presidente Figueiredo, Pedras River Waterfall: 1 nymph, 05.xi.2004 (INPA). BRAZIL, 
Espírito Santo, Sooretama, Reserva Biológica de Sooretama, Quirinão stream: 3 nymphs, 04.xi.2011, leaves (1 in IFML, 2 in UFES).OTHER MATERIAL EXAMINED: BRAZIL, Amazonas, Manaus, Reserva Florestal Ducke, Barro Branco stream 02 55'46.7"S 059 58'22.0"W: 1 female imago, 21.i.2010, P.V. Cruz col (UFES); 1 female imago, 16.iii.2010, light trap, Cleuder (INPA).

\section{Discussion}

Among South American representatives of Baetidae, the nymphs of Callibaetoides gen. nov. can be confused with those of Callibaetis by presenting slender legs and folded gills. The gills of Callibaetoides gen. nov. and Callibaetis are particularly similar with regard to the presence of a vestigial anal rib, a costal rib that is far from the costal margin, a ventrally-folded anal expansion, and the ability to make rhythmic movements. Besides that, some species of Callibaetis (e.g., C. capixaba Cruz, Salles \& Hamada, C. pollens Neddham \& Murphy and others not yet published) also have a labrum with a deep medial emargination and paraglossae apically truncated and longer than glossae, exactly as in Callibaetoides gen. nov., despite the similarities, Callibaetoides gen. nov. can be distinguished from Callibaetis by its three-segmented maxillary palp labial palp with a dorsal surface flat, and not concave.

Among genera from outside South America, nymphs of the new genus can be confused with those of the Neartic, Palaearctic, and Oriental genus Pseudocentroptiloides Jacob and Glazaczow, especially if we consider the same characteristics shared with some species of Callibaetis (slender legs, labrum with a deep medial emargination, paraglossae apically truncated and longer than glossae,) and the third segment of the labial palp being quadrangular. However, Callibaetoides gen. nov. is excluded from the Cloeon Complex of genera of which Pseudocentroptiloides is a member, by its not expanded third segment of labial palp (Waltz and McCafferty, 1989) and absence of spines on lateral margin of abdominal segments (Kluge and Novikova, 1992; Hill et al., 2010; Kluge, 2011). The same combination of characteristics, along with the absence of an apical projection on labial palp segment 3 allows differentiation between Callibaetoides gen. nov. and Waynokiops Hill et al. (2010).

Surprisingly, the taxon most similar to Callibaetoides caaigua is Centroptilum elongatum Suter (1986), an unusual species of Centroptilum from Australia described based on male imago and nymph. They both have a labrum with a deep medial emargination, the third segment of the labial palp quadrangular, the maxilla with a three segmented palp and mandibles with incisors deeply cleft. However, it is difficult to ascertain at this time if these similarities are an example of convergence, as between Callibaetoides gen. nov., Callibaetis and Pseudocentroptiloides, or an indication that the species are related. Affinities between Neotropical and Australasian faunas have been reported in four families of mayflies (Ameletopsidae, Coloburiscidae, Nesameletidae, and Oniscigastridae), but this possible kind of affinity has never been reported in Baetidae (Barber-James et al. 2008), with the exception of Cloeodes and Bungona Harker an Australasian genus which are related (Suter and Pearson, 2001). However, species of Cloeodes are also reported from other biogeographical realms, such as Afrotropics (Waltz and MacCafferty, 1994), Nearctic (Waltz and MacCafferty, 1987), and Orient (Soldán and Yang, 2003).

The male imago of Callibaetoides gen. nov. does not show similarity with known male imagos of Callibaetis or Pseudocentroptiloides. In Callibaetis, the body is usually covered with small red spots, the hind wing has three longitudinal veins and the costal process of the hind wing is relatively shorter and located on the basal third. In Callibaetoides gen. nov., on the other hand, the body is devoid of red spots, the hind wing is extremely reduced with two longitudinal veins, and the costal process of the hind wing has an inverted L-shape centrally located. Besides that, in male imagos of Pseudocentroptiloides marginal intercalary veins are single, forceps have a distinct inner tubercle on the second segment and the subgenital plate is broad and flattened, while in male imagos of Callibaetoides gen. nov. the marginal intercalary veins are double and peculiarly long, the forceps lack a distinct inner tubercle on the second segment, and the subgenital plate has a small rounded projection. The peculiar long intercalary veins are also present in Cloeodes auwe Salles \& Batista male imago (not yet published).

The unusual sexual dimorphism can be seen in the number of forewing marginal intercalary veins, occurring single in female and double in male. Although intriguing this can be found in Cloeodes barituensis Nieto \& Richard (2008) and other species of Cloeodes and Callibaetis (not yet published).

Acknowledgements. We thank Coordenação de Aperfeiçoamento de Pessoal de Nível Superior (CAPES); Conselho Nacional de Desenvolvimento Científico e Tecnológico (CNPq) processes number 313117/2009-8, 470731/2009-5, Protax processes number 52/2010 and Programa de Capacitação Institucional for providing fellowship to the authors.

Financial support was provided by research projects supported by 'Insetos aquáticos: biodiversidade, ferramentas ambientais e a popularização da ciência para melhoria da qualidade de vida humana no Estado do Amazonas' PRONEX-CNPqFAPEAM/INPA (MCT) and Fundação de Apoio à Ciência e Tecnologia do Espírito Santo (FAPES) processes number $3632763 / 07,45429502 / 09$. Resources for the equipment used in this study were provided by (CAPES)/Pró-equipamento. Electron microscopy photographs were provided by Laboratório Temático de Microscopia Óptica e Eletrônica (LTMOE)/INPA. We also thank the staff of Reserva Biológica de Sooretama, ICMBio (Instituto Chico Mendes de Conservação da Biodiversidade); IBAMA (Instituto Brasileiro do Meio Ambiente e dos Recursos Naturais Renováveis) for collecting permits (numbers 27255-1, 11239-1, 16719-1, 12777-1) and the valuable suggestions of Dr Luke M. Jacobus and Dr Jean-Luc Gattollia. 


\section{References}

Barber-James H.M., Gattolliat J.-L., Sartori M. and Hubbard M.D., 2008. Global diversity of mayflies (Ephemeroptera, Insecta) in freshwater. Hydrobiologia, 595, 339-350.

Coleman C.O., 2003. "Digital inking": How to make perfect line drawings on computers. Org. Divers. Evol., Electron. Suppl., 1-14. Available online at: http://senckenberg.de/odes/ 03-14.htm

Coleman C.O., 2006. Substituting time-consuming pencil drawings in arthropod taxonomy using stacks of digital photographs. Zootaxa, 1360, 61-68.

Cruz P.V., Salles F.F. and Hamada N., 2009. Two new species of Callibaetis Eaton (Ephemeroptera: Baetidae) from Southeastern Brazil. Zootaxa, 2261, 23-38.

Cruz P.V., Boldrini R. and Salles F.F., 2011a. Apobaetis Day (Ephemeroptera: Baetidae) from northern Brazil: description of a new species and of the male imago of $A$. fiuzai Salles and Lugo-Ortiz. Aquat. Insects, 33, 81-90.

Cruz P.V., Boldrini R., Salles F.F. and Hamada N., 2011b. The male imago of Rivudiva trichobasis Lugo-Ortiz and McCafferty from Amazonas state, Brazil. Zootaxa, 2907, 60-62.

Dallwitz M.J., 1980. A general system for coding taxonomic descriptions. Taxon, 29, 41-46.

Domínguez E., Molineri C., Pescador M.L., Hubbard M.D. and Nieto C., 2006. Ephemeroptera of South America. Aquatic Biodiversity of Latin América. ABLA Series, ISSN 13127276. Volume 2, $642 \mathrm{p}$.

Edmunds G.F.JR., Jensen S.L. and Berner L., 1976. The Mayflies of North and Central America, University of Minnesota Press, Minneapolis. $\mathrm{x}+330 \mathrm{p}$.

Falcão J.N., Salles F.F. and Hamada N., 2010. The adults of Harpagobaetis Mol and Tomedontus Lugo-Ortiz and McCafferty (Ephemeroptera: Baetidae) with notes on the nymphal stage. Zootaxa, 2530, 39-46.

Gattolliat J.L. and Nieto C., 2009. The family Baetidae (Insecta: Ephemeroptera): synthesis and future challenges. Aquat. Insects, 31, Supplement 1, 41-62.

Hill M.A., Pfeiffer J. and Jacobus L.M., 2010. A new genus and new species of Baetidae (Ephemeroptera) from lakes and reservoirs in eastern North America. Zootaxa, 2481, 61-68.

Hubbard M.D., 1995. Toward a standard methodology for the description of mayflies (Ephemeroptera). In: Corkum L.D. and Ciborowski J.J.H. (eds.), Current Directions in Research on Ephemeroptera, Canadian Scholars' Press Inc., Toronto, 361-369.

Kluge N.J. 2011. Non-African representatives of the plesiomorphion Protopatellata (Ephemeroptera: Baetidae). Russ. Entomol. J., 20, 361-376.

Kluge N. and Novikova E.A., 1992. Revision of Palearctic genera and subgenera of mayflies in the subfamily Cloeoninae (Ephemeroptera, Baetidae) with descriptions of new species from the USSR. Entomol. Oboz., 71, 60-83.

Lugo-Ortiz C.R. and McCafferty W.P. 1995. Three distinctive new genera of Baetidae (Insecta, Ephemeroptera) from South America. Ann. Limnol. - Int. J. Lim., 31, 233-243.

Lugo-Ortiz C.R. and McCafferty W.P., 1996a. Aturbina georgei gen. et sp. n.: A small minnow mayfly (Ephemeroptera: Baetidae) without turbinate eyes. Aquat. Insects, 18, 175-183.
Lugo-Ortiz C.R. and McCafferty W.P., 1996b. Phylogeny and classification of the Baetodes complex (Ephemeroptera: Baetidae), with description of a new genus. J. N. Am. benthol. Soc., 15, 367380 .

Lugo-Ortiz C.R. and McCafferty W.P., 1996c. New species of Leptophlebiidae (Ephemeroptera) from Mexico and Central America. Ann. Limnol. - Int. J. Lim., 32, 3-18.

Lugo-Ortiz C.R. and McCafferty W.P., 1996d. The genus Paracloeodes (Insecta: Ephemeroptera : Baetidae) and its presence in South America. Ann. Limnol. - Int. J. Lim., 32, 161-169.

Lugo-Ortiz C.R. and McCafferty W.P. 1996e. Taxonomy of the neotropical genus Americabaetis, new status (Insecta: Ephemeroptera: Baetidae). Stud. Neotrop. Fauna Environ., 31, 156-169.

Lugo-Ortiz C.R. and McCafferty W.P., 1997. First report and new species of the genus Apobaetis (Ephemeroptera: Baetidae) from South America. Aquat. Insects, 19, 243-246.

Nieto C. and Richard B., 2008. The genus Cloeodes (Ephemeroptera: Baetidae) in Argentina with new generic synonymy and new species. Zootaxa, 1727, 1-21.

Nieto C. and Salles F.F., 2006. Revision of the genus Paracloeodes (Ephemeroptera: Baetidae) in South America. Zootaxa, 1301, 1-33.

Nieto C., 2010. Cladistic analysis of the family Baetidae (Insecta: Ephemeroptera) in South America. Syst. Entomol., 35, 512-525.

Nieto C. and Derka T., 2011. Parakari a new genus of the family Baetidae (Insecta: Ephemeroptera) from Guyana Highlands. Zootaxa, 3032, 47-59.

Salles F.F., 2007. The presence of Chane Nieto and Guajirolus flowers (Ephemeroptera, Baetidae) in Brazil with the description of a new species. Rev. Bras. Entomol., 51, 404-409.

Salles F.F. and Batista J.D., 2004. The presence of Varipes Lugo-Ortiz and McCafferty (Ephemeroptera: Baetidae) in Brazil, with the description of a new species. Zootaxa, 456, $1-6$.

Salles F.F. and Francischetti C.N., 2004. Cryptonympha dasilvai sp. nov. (Ephemeroptera: Baetidae) do Brasil. Neotrop. Entomol., 33, 213-216.

Salles F.F. and Polegatto C.M., 2008. Two new species of Baetodes Needham and Murphy (Ephemeroptera: Baetidae) from Brazil. Zootaxa, 1851, 43-50.

Salles F.F., Batista J.D. and Cabette H.R.S., 2004. Baetidae (Insecta: Ephemeroptera) de Nova Xavantina, Mato Grosso, Brasil: novos registros e descrição de uma nova espécie de Cloeodes Traver. Biota Neotropica., 4, 1-8.

Salles F.F., Andrade M.B. and Da-Silva, E.R., 2005. Camelobaetidius francischettii: a new species of Baetidae (Ephemeroptera) from Brazil. Zootaxa, 1027, 47-53.

Salles F.F., Boldrini R., Shimano Y. and Cabette H.R.S., 2011. Review of the genus Aturbina Lugo-Ortiz and McCafferty (Ephemeroptera: Baetidae). Ann. Limnol. - Int. J. Lim., 47, 21-44.

Soldán, T. and Yang J-T., 2003. Mayflies (Ephemeroptera) of Taiwan: Species composition, toxonomic shifts, distribution and biogeographical analysis. In: Gaino E. (ed.), Research Update on Ephemeroptera \& Plecoptera, Università di Perugia, Italy, pp. 413-420.

Suter P.J., 1986. The Ephemeroptera (mayflies) of South Australia. Rec. South Aust. Mus., 19, 339-397. 
Suter P.J. and Pearson M.J., 2001. Redescription of Bungona Harker with new synonyms in the Australian Baetidae (Insecta Ephemeroptera). Mem. Museum Victoria, 58, 247-254.

Waltz R.D. and McCafferty W.P., 1987. Generic revision of Cloeodes and description of two new genera (Ephemeroptera: Baetidae). Proc. Entomol. Soc. Washington, 89, 177-184.
Waltz R.D. and McCafferty W.P., 1989. New species redescriptions, and cladisitics of the genus Pseudocentroptiloides (Ephemeroptera: Baetidae). J. New York Entomol. Soc., 97, 151-158.

Waltz R.D. and McCafferty W.P., 1994. Cloeodes (Ephemeroptera: Baetidae) in Africa. Aquat. Insects, 16, 165-169. 